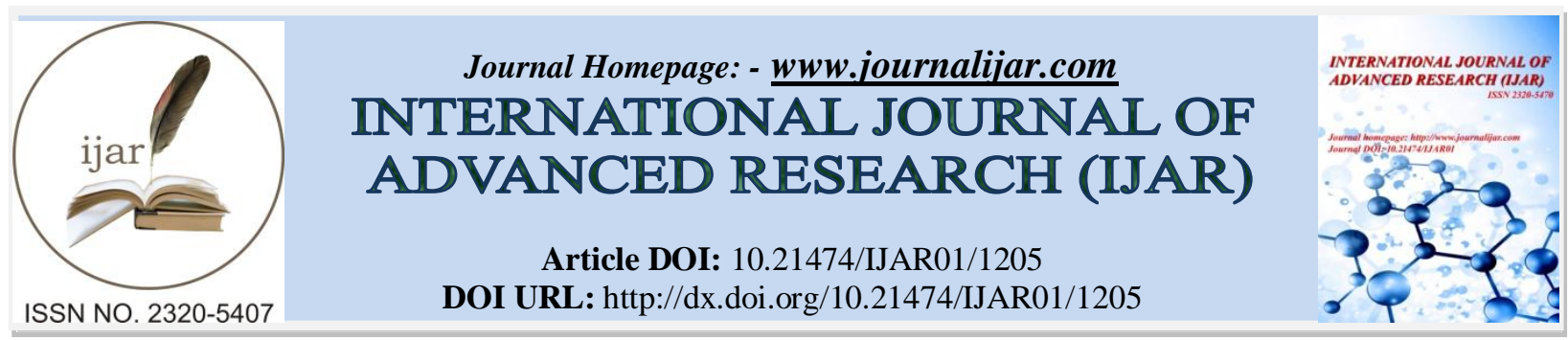

RESEARCH ARTICLE

\title{
IN VITRO EVALUATION OF ANTI-CANCER ACTIVITY OF CURCUMINOIDS FROM TURMERIC (CURCUMA LONGA L.) AGAINST MULTIDRUG RESISTANT TUMOR CELL LINES.
}

\author{
S. Revathy ${ }^{1 *}$, S.Elumalai ${ }^{2}$. \\ 1. Department of Plant Biology and Biotechnology, Presidency College (Autonomous), Chennai -600 005 Tamil \\ Nadu, India. \\ 2. Department of Biotechnology, University of Madras, Guindy campus, Chennai -600 025 Tamil Nadu, India.
}

\section{Manuscript Info}

Manuscript History

Received: 19 June 2016

Final Accepted: 22 July 2016

Published: August 2016

Key words:-

curcuminoids, chemotherapy, drug

resistance, cancer cell lines, anticancer.

\section{Abstract}

Cervical cancer is the second most common cancers among women worldwide. Chemotherapy is the treatment of cancer with one or more cytotoxic drugs as part of a standard regimen. One of the major causes of chemotherapy failure in cancer treatment is multidrug resistance (MDR). It shows resistance to general anticancer drugs used and shows cross resistant to many different structurally unrelated drugs causing multidrug resistance. MDR is over expression of the ATP-binding cassette (ABC) transporters (efflux pump) such as p-glycoprotein (ABCB1 / p-gp). To overcome drug resistance most obvious response that widely employed is to use combination drug therapy. The association of phytochemicals with chemotherapy shows synergistic effects that target simultaneously multiple pathways and help to kill cancer cells and slowdown the onset of drug resistance. The present study was undertaken to assess the chemotherapeutic activity of curcuminoids against the cervical carcinoma cell line HeLa and drug resistant cell lines. Curcuminoids have broad spectrum of pharmacological properties. The $\mathrm{IC}_{50}$ values of curcuminoids revealed that curcumin had a higher cytotoxicity against $\mathrm{HeLa}$ cell lines $\left(\mathrm{IC}_{50}=4.30 \mu \mathrm{g} / \mathrm{ml}\right)$ than $\mathrm{DMC}$ and $\mathrm{BDMC}$ are $\left(\mathrm{IC}_{50}=>100\right.$ and $10.43 \mu \mathrm{M})$ respectively. The cytotoxicity of curcuminoids against drug resistant cell lines revealed that higher cytotoxicity at BDMC treatment at $\mathrm{IC}_{50}=7.8$ and $5.2 \mu \mathrm{M}$ on $\mathrm{KB}$ and $\mathrm{KBChR} 8-5$ respectively. Therefore BDMC act on MDR cell lines more effectively than other curcuminoids which revealed that it may have synergistic effect that target the pathway related to multidrug resistance and block the efflux pump to increase the accumulation of anticancer drugs and induce cytotoxicity.

Copy Right, IJAR, 2016,. All rights reserved.

\section{Introduction:-}

Cancer is a major worldwide public health problem. Cervical cancer is the most commonly diagnosed malignancy in women ranks second among women population. It is the cancer that forms in tissues of the cervix and usually a slow growing cancer. Some of the drugs used for cervical cancer chemotherapy include 5-fluro uracil (5FU), cisplatin, carboplatin, infosfamide, paclitaxel and cyclophophamide (Kim et al., 2009). When cancer comes back after 
treatment it is called cancer recurrence, in such cases patients should get regular treatments with chemotherapy, radiation therapy throughout their life time. One of the reasons for cancer recurrence may be development of drug resistance to common chemotherapeutic drugs used in cancer treatment. Human increasingly employs chemicals as chemotherapeutic agents to treat cancer; the repeated use of these chemicals often leads to becoming ineffective due to other onset of resistance by the target cells.

Tumor cells that are initially sensitive to a broad range of drugs can frequently develop resistance to a group of anticancer drugs. (Gottesman and Ling, 2006). The human multidrug-resistance (MDR1) gene encodes a membrane transporter p-glycoprotein (p-gp) a member of ATP binding cassette family (Borst et al., 2000). The expression of MDR gene plays important role in multidrug resistant phenotype and also confers to cross resistance to a large group of lipophilic cytotoxic compounds. Multidrug resistance in human and rodent cell lines results in decreased intracellular drug accumulation and correlates with the increased expression of MDR genes due to the presence of efflux pump (Gottesman and Pastan, 1988).

The basis of drug resistance have been studied in laboratory using drug resistance cell lines that have been isolated by exposing to increasing amounts of any one of the chemotherapeutic agents to various cancer cells in order to develop resistance to that particular drug (Ling and Thompson, 1974). These isolated resistant cells are frequently resistant to particular drug but also shows cross resistant to other drugs.

Akiyama et al., screened human cultured cancer cells for two properties: high efficiency of cloning and sensitivity to common MDR drugs such as colchicine, vinblastine and doxorubicin. (Akiyama et al., 1985). It was actually a subclone of HeLa, a cervical adenocarcinoma cell line that had contaminated and overgrown quite a few putative human cancer cell lines and had contaminated and distributed as KB (Nelson-Rees and Flandermeyer., 1976). The growth properties and drug sensitivity on HeLa (KB) has proved to be a very useful human cancer cell line for studying development of drug resistance (Boshart et al., 1984).

A large number of non cytotoxic compounds known as chemosensitizers or MDR modulators sensitize resistant cells for the action of cytotoxic drugs. Several generations of $\mathrm{p}$-gp modulators are developed in reversing $\mathrm{p}$-gp mediated multidrug resistance (MDR). The basic strategy to circumvent MDR is to co-administration of an anticancer drug with a chemosensitizer that impairs p-gp function resulting in enhanced intracellular anticancer drug accumulation (Leonard et al., 2002). It is necessary to identify natural compounds from plant origin that reverse the MDR phenotype, sensitize cancer cells to conventional chemotherapy without undesired toxicological effects. Dietary phytochemicals have been found to be very promising in reversing the resistance to anticancer.

Curcuma longa L. (turmeric) is a typical herbaceous plant that characterizes the family Zingiberaceae. Curcumin (C), main colouring substance in Curcuma longa L. and two related compounds, demethoxycurcumin (DMC) and bisdemethoxycurcumin (BDMC), were altogether known as curcuminoids (Govindarajan, 1980). The total of curcuminoids which are about 4-6\%, turmeric also contains 2-4\% essential oil and various volatile oils, including turmerone, atlantone, and zingiberone (Merina Benny Antony, 2003). Since the curcuminoid pigments vary in chemical structures, it is possible that the physico- chemical characteristics as well as the functional properties and biological role of curcuminoids would vary among them. The extraction of curcuminoids were done by soxhlet extraction of turmeric powder with acetone gave a yield of about 5.0\% containing $43 \%$ curcuminoids in 4 to 6 hours. (Revathy et al., 2011). A number of studies are undertaken to separate curcuminoid pigments by thin layer chromatography (TLC), high-performance thin-layer chromatography (HPTLC), and column chromatography (CC) (Gupta et al., 1999). HPLC method was sensitive, precise, and accurate for detection and quantification of curcuminoids in the extract of rhizome Curcuma longa L. (Sompol et al., 2009). Characterization of compounds by GC-MS, FTIR, NMR confirms the identity of curcuminoids. The cytotoxicity of drugs were analysed by MTT Assay (Mosmann, 1983) is a sensitive, quantitative and reliable colorimetric assay that measures viability, proliferation and activation of cells.

In the present study we have demonstrated extraction, identification, purification and characterization of curcuminoids from turmeric rhizome. Further we have examined the cytotoxic properties of individual curcuminoids on drug resistance cell line. 


\begin{abstract}
Materials and Methods:-
Extraction of curcuminoids:-

Curcuma longa L. (Turmeric) rhizome was collected from Assam - Lakhadong variety. Fresh rhizomes were cleaned, washed, dried and blended to powder. About $20 \mathrm{~g}$ of turmeric powder was taken into a thimble and placed in a soxhlet apparatus and extracted using acetone as solvent for 6 hours. The dark brown extract yielded was then cooled, filtered, concentrated using rotary evaporator. Extracts were analysed for curcuminoids by HPLC analysis.

Extract were tested in TLC pre-coated silica gel (Merk-60 F254,0.25mm thick) plate developed using a camag twin trough glass tank with the mobile phase Chloroform:methanol (95:5) and the plate was developed to a height of about $10 \mathrm{~cm}$. After development, plates were removed and dried and spots were visualized in UV light.
\end{abstract}

\title{
Column chromatography:-
}

About $5 \mathrm{gm}$ of crude Curcuminoids were mixed with $8 \mathrm{gm}$ of silica gel and loaded on to the glass column (60-120 mesh) and eluted with chloroform followed by chloroform:methanol with increasing polarity. All the collected fractions were subjected to TLC silica gel 60 F254 plate using chloroform:methanol (95:5) as the developing solvent system and detected as yellow spots. And fractions with similar Rf values were pooled and the organic solvent was removed by rotary evaporator.

Purification of each curcuminoids:-

The individual Curcuminoids collected from the column chromatography was dissolved in methanol and heated. After complete dissolution chloroform was added to get the ratio methanol:Chloroform 5:2 and kept at $5^{\circ} \mathrm{C}$ for overnight. The crystals obtained were separated by filtration. The crystals were precipitated with petroleum ether. The purity of Individual crystals were analysed in HPLC.

\section{Characterization of Curcuminoids:-}

Estimation of Curcuminoids by HPLC analysis:-

Weighed accurately $25 \mathrm{mg}$ sample and dissolved in $25 \mathrm{ml}$ acetone Filtered through $0.2 \mathrm{~m}$ membrane filter before injection. Samples were analysed by HPLC in a Shimadzer LC 20 A0 liquid chromatograph system with SPD$\mathrm{M} 20 \mathrm{AuV}$ detector in isocratic mode. $20 \mu \mathrm{l}$ of sample was injected and the elution was carried out with gradient solvent systems with a Column used was C18 (250X4.6mm), mobile phase 40\% THF and 60\% water containing $1 \%$ citric acid, $\mathrm{pH}$ adjusted to 3.0 using concentrated potassium hydroxide solution and measured in wavelength of 420nm. (Cooper et al., 1994).

Gas chromatography - Mass Spectrometer (GC-MS):-

Molecular weight of compounds was analysed by GC-MS using JOEL GCMATE II GC Mass spectrometer. Each curcuminoids were dissolved in methanol, the solution was then injected. Perfluorokerosene (PFK) is used as reference sample (Biemann, 1962).

Fourier Transform - Infra Red Spectroscopy (FTIR):-

Curcuminoids samples are dispersed in $100 \mathrm{mg} \mathrm{KBr}$ and pressed to form a pellet and analysed on Perkin Elmer Spectrum One FT-IR instrument. (Colthup, 1990).

Nuclear Magnetic Resonance Spectroscopy (NMR):-

Spectra of $13 \mathrm{C}$ and $1 \mathrm{H}$ were determined in DMSO-d6, operating at 200 and $50 \mathrm{MHz}$ respectively, using JEOL GSX400 NMR spectrometer. Tetramethyl silane (TMS) was used as internal standard. (Slichter, 1990).

\section{Cell culture:-}

The KB, KB-ChR-8-5 human cervical carcinoma cell lines and HeLa cell lines were purchased from NCCS Pune, Maharashtra, India. The cell lines were cultured in Dulbecco 's modified Eagle s medium (DMEM) with 2mM Lglutamine, $10 \%$ fetal calf serum (FCS), $1.5 \mathrm{~g} / \mathrm{L}$ sodium bicarbonate, $1 \mathrm{mM}$ non-essential amino acid and $1.0 \mathrm{mM}$ sodium pyruvate. Only the KBChR8-5 cell line was routinely maintained in 10ng/ml colchicines and subsequently grown in colchicine-free medium for one week prior to drug treatment. The cell lines were maintained in a humidified incubator with an atmosphere of $5 \%$ air and $5 \% \mathrm{CO}_{2}$ at $37^{\circ} \mathrm{C}$. 


\section{Real-time PCR:-}

Total cellular RNA from KB and KBChR8-5 cells were extracted by TRIzol Reagent (Chomvzynski et al., 1987). (Invitrogen, Carlsbad, CA, USA) and treated with RQ1 RNase-free DNase. Total RNA was reverse-transcribed to generate cDNA using RT-PCR kit (Promega Corporation, Madison, USA). The cDNA pool was subjected to QRTPCR by using SYBR green PCR Master Mix on the AB 7500 fast real time PCR system (Applied Biosystems), Primers for MDR1 gene forward primer sequence CAGAGCAAGAGAGGCATCCT and the reverse primer sequence TGAAGGTCTCAAACATGAT and GAPDH were used as internal control,

Table 1:- The reaction mixture was prepared as follow.

\begin{tabular}{|l|c|}
\hline $10 \mathrm{x}$ PCR buffer with $\mathrm{MgCl}_{2}$ & $5 \mu \mathrm{l}$ \\
\hline $10 \mathrm{mM}$ dNTP mix & $1 \mu \mathrm{l}$ \\
\hline $10 \mu \mathrm{M}$ forward primer & $5 \mu \mathrm{l}$ \\
\hline $10 \mu \mathrm{M}$ reverse primer & $5 \mu \mathrm{l}$ \\
\hline cDNA & $5 \mu \mathrm{l}$ \\
\hline Taq polymerase $(5 \mathrm{U} / \mu \mathrm{l})$ & $0.2 \mu \mathrm{l}$ \\
\hline Nuclease free water & $28.8 \mu \mathrm{l}$ \\
\hline Final reaction volume & $50 \mu \mathrm{l}$ \\
\hline
\end{tabular}

\section{Polymerase chain reaction $(\mathrm{PCR})$ :-}

40 cycles of amplification were done and water was amplified for negative control. The following conditions were used in QPCR: $2 \mathrm{~min}$ at $50^{\circ} \mathrm{C}, 10 \mathrm{~min}$ at $95^{\circ} \mathrm{C}$, and 40 cycles of $15 \mathrm{~s}$ at $95^{\circ} \mathrm{C}$ and $1 \mathrm{~min}$ at $60^{\circ} \mathrm{C}$. Total $10 \mu \mathrm{L}$ of each PCR product as well as DNA Ladder was electrophoresed in $1 \mathrm{X}$ Tris/acetate/EDTA (TAE) electrophoresis buffer on a $1 \%$ agarose gel at 100 volts for 20-30 minutes, visualized using UV transillumiator and photographed after staining with Ethidium bromide (Huang et al., 2006).

\section{MTT assay procedure:-}

The MTT [3-(4,5-dimethy-2-thiazoly)-2, 5-diphenyl-2H-tetrazolium bromide] assay was used to determine drug sensitivity. (James et al., 1987). KB, KBChR8-5 and HeLa cells in the exponential growth phase were harvested by trypsinization and seeded into 96-well plate at a concentration of 3500 cells per well. The cells were treated in triplicate with gradient concentration of curcuminoids ranging from $0.01 \mu \mathrm{g}, 0.1 \mu \mathrm{g}, 1.0,10$ and $100 \mu \mathrm{g}$ and incubated at $37^{\circ} \mathrm{C}$ for 24 hours. The $\mathrm{IC}_{50}$ value defined as the drug concentration required to reduce cell survival to $50 \%$ as determined by the relative absorbance of MTT. IC $_{50}$ value was calculated by (mean absorbance in test wells) / (mean absorbance in control wells) x 100 .

\section{Results:-}

\section{Characterization of curcuminoids High - Performance Liquid Chromatography (HPLC):-}

In our study the total extract contained $40.1 \%$ of curcuminoids were found in Assam variety turmeric among that $23.9 \%$ curcumin, $10 \%$ DMC $6.1 \%$ BDMC by HPLC analysis. The purity profile of isolated individual curcuminoids were analysed by HPLC. C, DMC, BDMC showed single peaks at retention times of 10.81, 12.79 and 13.03 min respectively. The identity of each peak was confirmed by determination of retention times and by spiking with standards. Purity profile for each curcuminoids were calculated as 99\%, 98\%, 95\% purity for C, DMC, BDMC respectively.

\section{GC-MS:-}

The full scan mass spectra of each curcuminoids isolated were detected shows molecular weight of each individual compounds of C, DMC, BDMC was found to be $368.31,337.77$, and 307.95 respectively.

\section{FT-IR analysis:-}

The presence of absorption bands of specific stretching regions obtained at their respective frequency confirms the structure of compounds. IR absorption bands (cm-1)

For $\mathbf{C}$ showed 3413.76(O-H str); 1629.14(conjugated $\mathrm{C}=\mathrm{C}$ str); 1585.60 (-unsaturated $\mathrm{C}=\mathrm{O}$ str); 1455.64 (aromatic ring str); 1288.65, 1028.68 (=C-O-CH3 str); 1140.52 (C-OH str). 
For DMC showed 3326.98 (O-H str); 1627.30 (conjugated $\mathrm{C}=\mathrm{C}$ str); 1575.24 (-unsaturated $\mathrm{C}=\mathrm{O}$ str); 1437.33 (aromatic ring str); 1263.07, 1025.21 (=CO- CH3 str); 1134.67 (C-OH str).

For BDMC showed 3230.06 (O-H str); 1629.40 (conjugated $\mathrm{C}=\mathrm{C}$ str); 1575.64 (-unsaturated $\mathrm{C}=\mathrm{O}$ str); 1508.90 (aromatic ring str); 1165.85 (C-OH str).

\section{NMR analysis:-}

${ }^{13}$ C NMR chemical shift (ppm): Curcumin 183.6, 149.8, 148.4, 141.1, 126.8, 123.5, 121.5, 116.1, 111.8, 101.2, 56.1 .

DMC- 183.7, 183.5, 160.27, 149.82, 148.47, 141.16, 140.83, 130.78, 126.82, 126.29, 123.61, 121.27, 116.39, $116.18,111.77,101.40,56.1$.

BDMC - 183.66, 160.26, 140.82, 130.78, 126.30, 121.25, 116.38 and 101.41. The presence of signal at 56.1 in C and DMC denotes the presence of methoxyl group while there is no methoxyl group present in BDMC.

${ }^{1}$ H NMR chemical shift (ppm): Curcumin 9.65, 7.57, 7.32, 7.16, 6.84, 6.77, 6.06, 3.84.

DMC- 10.03, 9.68, 7.57, 7.55, 7.33, 7.16, 7.14, 6.84, 6.78, 6.74, 6.04, 3.84.

BDMC- $10.04,7.57,7.53,6.83,6.71,6.04$. Signal corresponding to the methoxyl group at 3.84 is found in $\mathrm{C}$ and DMC and absent in BDMC.

This demonstrates crude curcuminoids has three major compounds curcumin, demethoxycurcumin, bisdemethoxycurcumin and that the purity of each curcuminoids is in the range of $95-99 \%$.

\section{Real time PCR:-}

Total RNA was extracted from KB and KBChR8-5 cells by TRIzol Reagent and converted into cDNA using cDNA synthesis kit. Quantitative Real-Time PCR was set up with Power SYBR Green Master-mix for MDR1 gene expression using gene specific primers. Expression of Genes was normalized to GAPDH and control cell line relative expression was normalized with respect to KB cDNA shown in (Fig. 1)

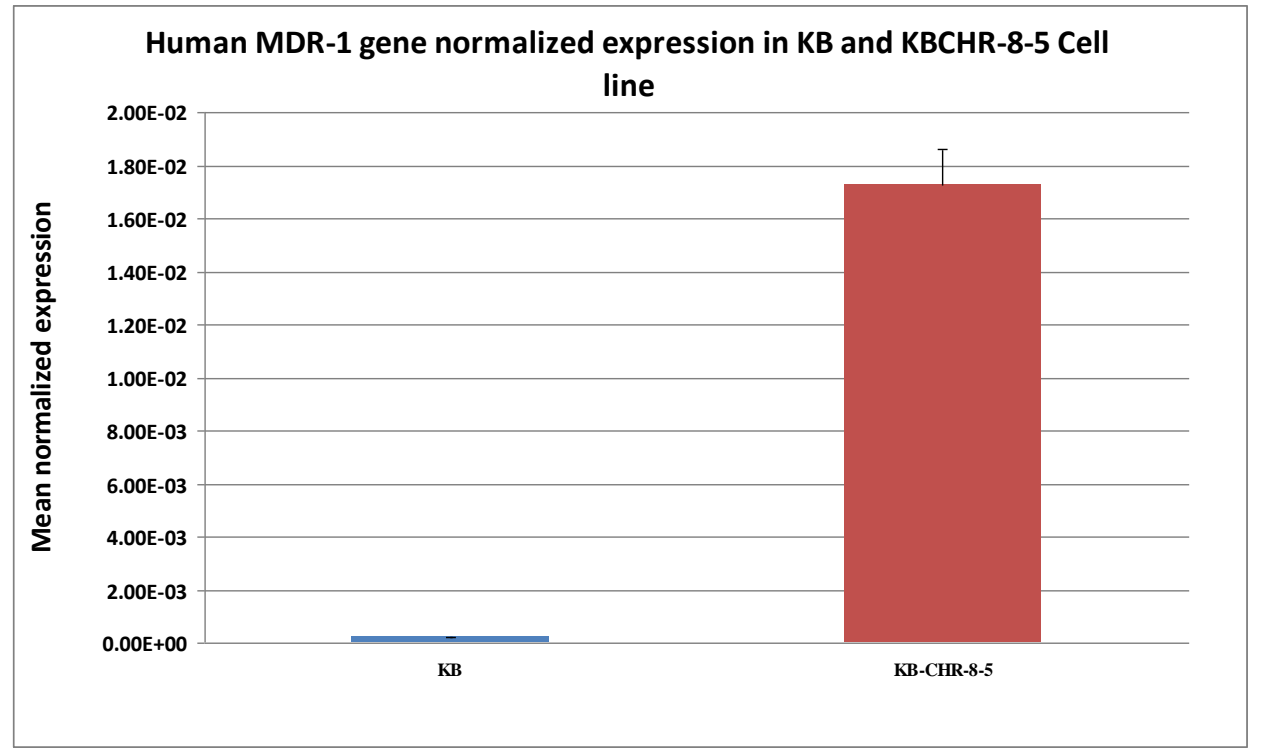

Fig 1:- HumanMDR1 gene expression analysis in KB and KBChR8-5 cells: MDR1 gene expression were measured and normalized to GAPDH expression, double distilled water $\left(\mathrm{DDH}_{2} \mathrm{O}\right)$ was used as a negative control. $\mathrm{KB}$ cell in lane 1, KBChR8-5 cell in lane 2, the data are means \pm SEM of three independent experiments, and significantly different from the vehicle control $(\mathrm{p}<0.05)$. 
MDR1 gene expression in KB and KBChR8-5 cells showed significant difference in expression level. KBChR8-5 cells showed greater expression with 7.1 fold increase from KB cells, whereas very mild expressions were detected in KB cells. The MDR1 gene expression normalized with GAPDH were analyzed by gel run, the band formed shown in (Fig. 2).

\section{Real time PCR analysis of MDR-1:-}

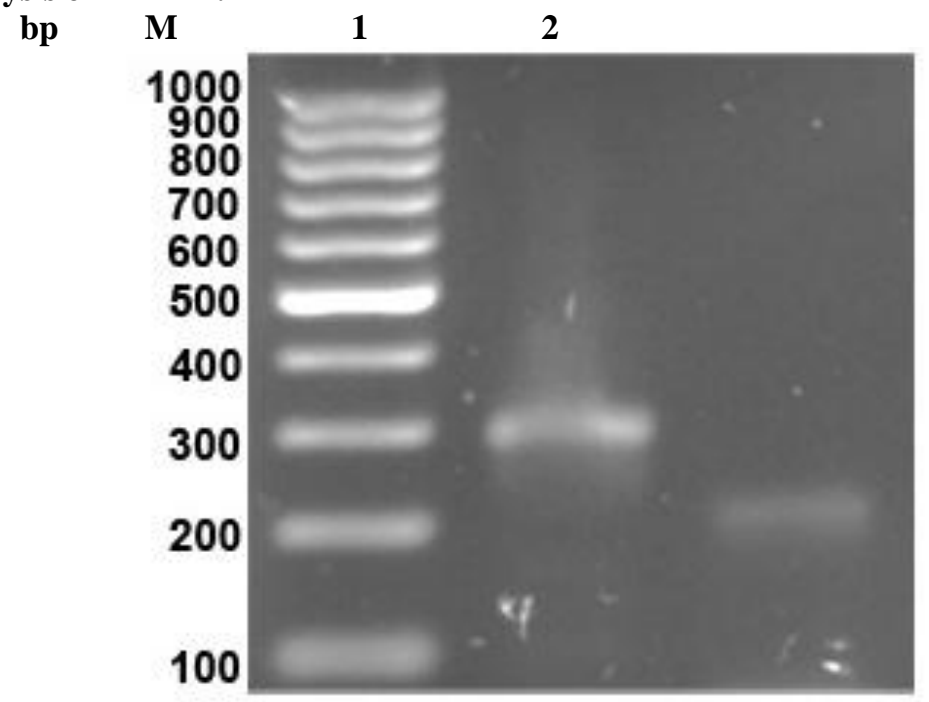

Marker: 100 bp DNA ladder

Lane 1: GAPDH - $294 \mathrm{bp}$

Lane 2: MDR - 1 - 202 bp

Fig 2:- Real-time PCR analysis of MDR-1 gene. PCR product was run in 1\% agarose gel and 100 bp DNA ladder was used as marker.

\section{MTT assay:-}

The dose response curve and the effect of three curcuminoids on KB, KBChR8-5 cell lines and HeLa were determined by cytotoxicity assay. Dose response cytotoxicity profiles for three curcuminoids C, DMC, and BDMC were established for KB, KBChR8-5 cell lines and HeLa were shown in figure $2 \mathrm{~A}, \mathrm{~B}, \mathrm{C}$. The percent of viable cells was calculated to determine the $\mathrm{IC}_{50}$. The $\mathrm{IC}_{50}$ value of $\mathrm{C}$, DMC, and $\mathrm{BDMC}$ in $\mathrm{KB}, \mathrm{KBChR} 8-5$ and HeLa cell lines is described in table 2.

Table 2:- Cytotoxicity of three curcuminoids in KB, KBChR8-5 and HeLa cell lines.

\begin{tabular}{|c|c|c|c|}
\hline \multirow{2}{*}{ Drugs } & KB & IC $_{\mathbf{5 0}} \boldsymbol{\mu M}$ & HeLa \\
\cline { 2 - 4 } & 18.3 & 19.2 & 4.30 \\
\hline C & 22.8 & 26.7 & $>100$ \\
\hline DMC & 7.8 & 5.2 & 10.43 \\
\hline BDMC & \multicolumn{3}{c|}{} \\
\hline
\end{tabular}


Fig 3:- Cytotoxic activity of Curcuminoids on KB, KBChR8-5 and HeLa cell lines

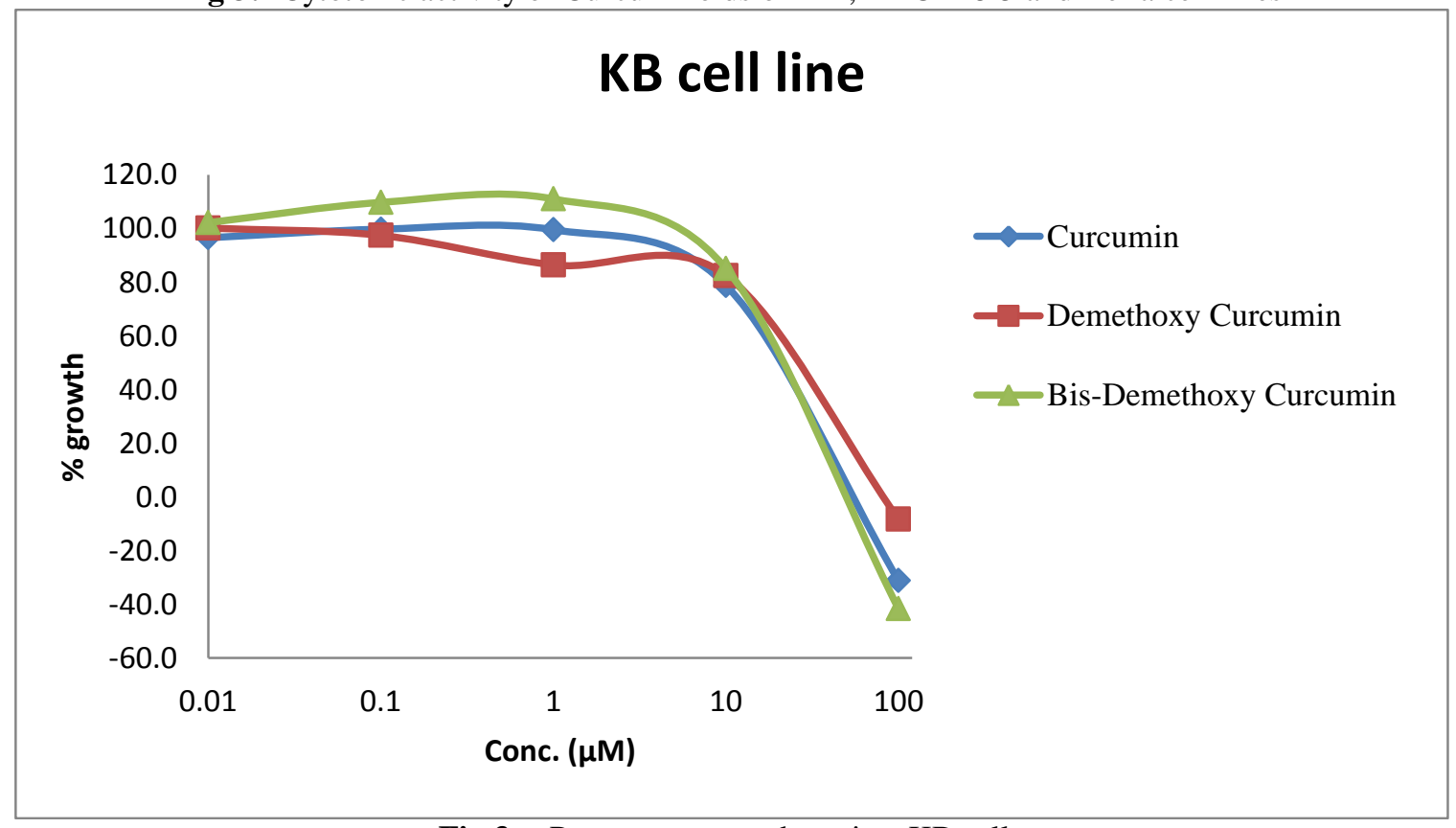

Fig.3a:-Percentage growth against KB cells

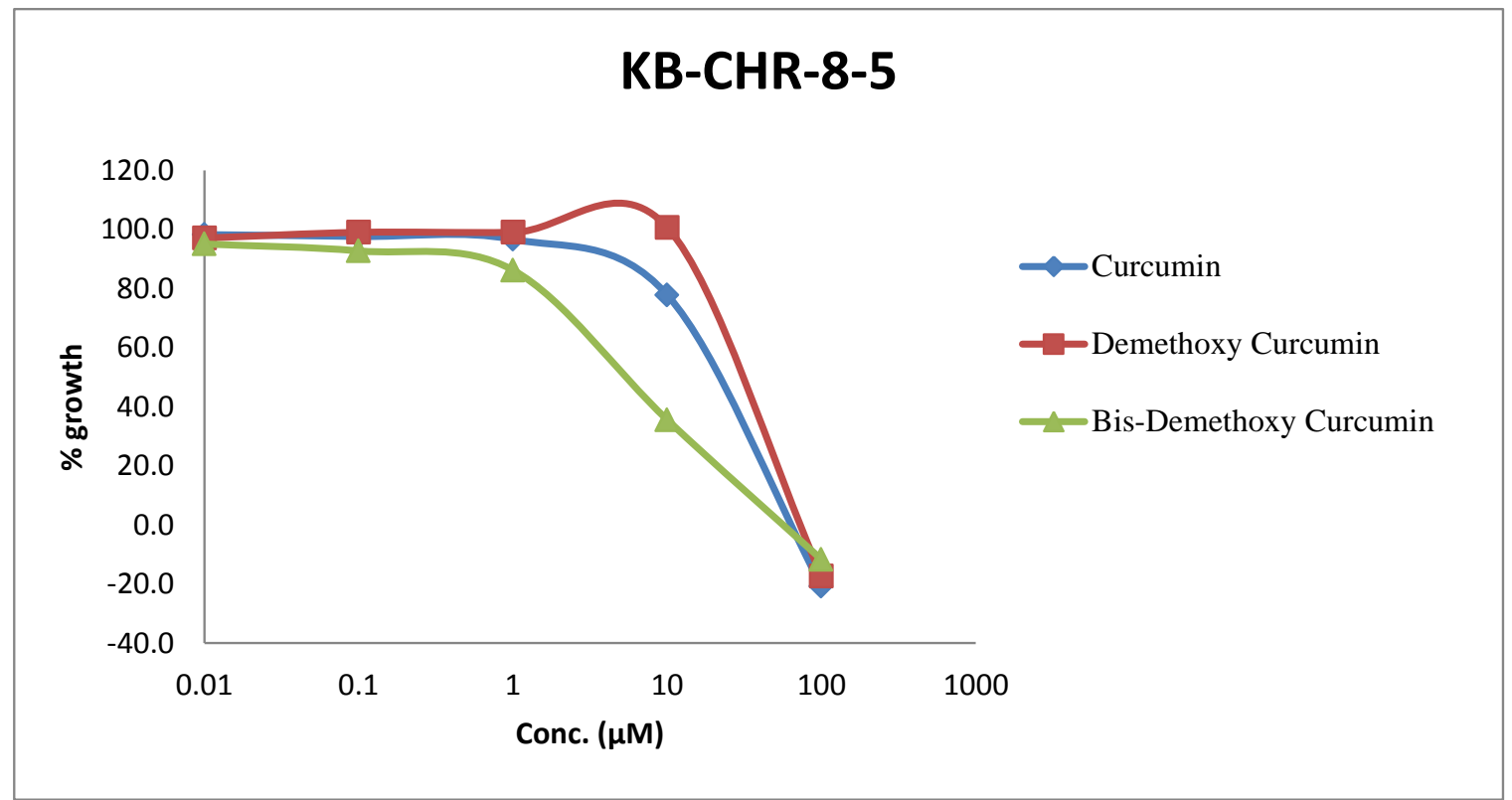

Figure.3b:- Percentage growth against KBChR8-5 cells. 


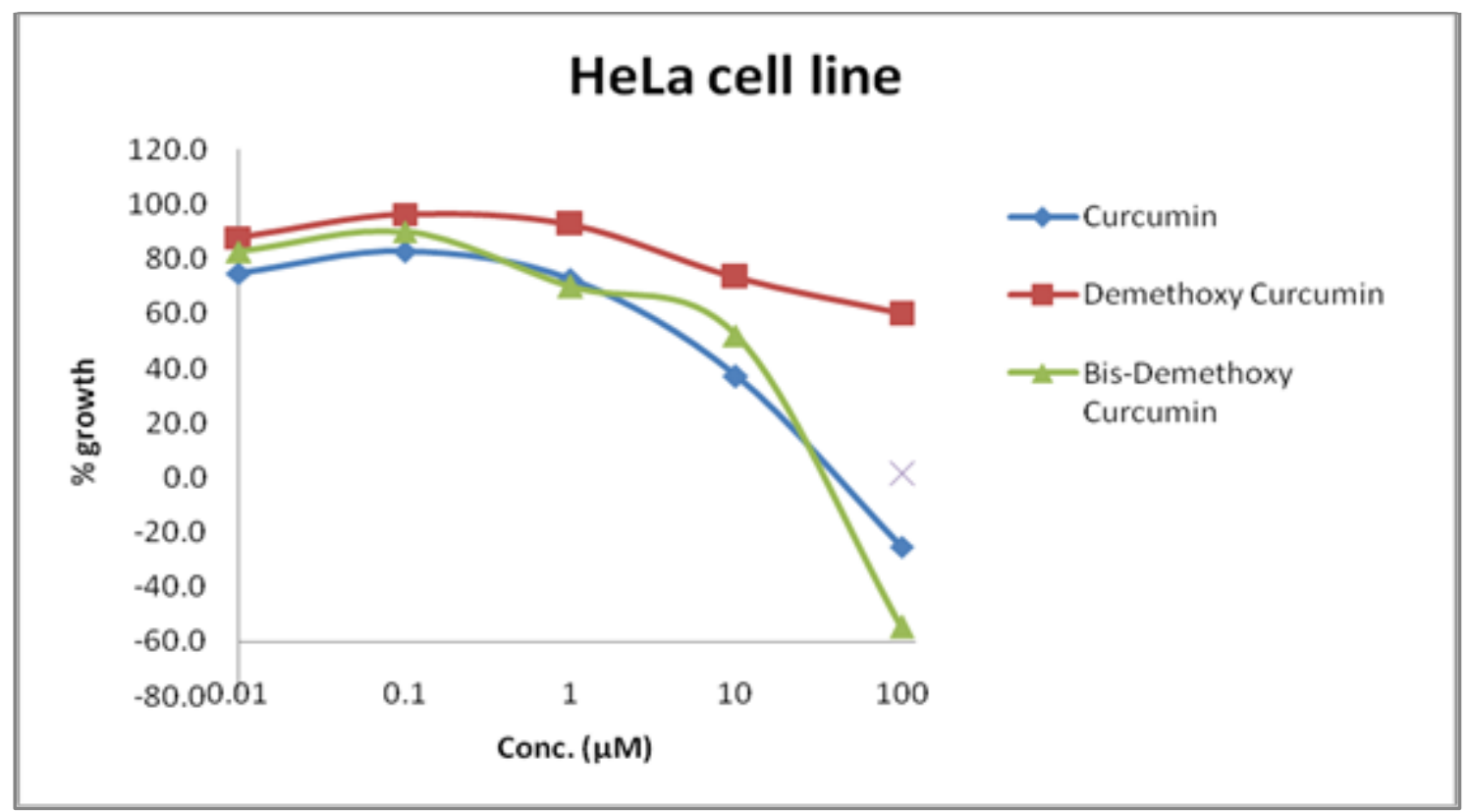

Figure.3c:- Percentage growth against HeLa cells.

Fig.3:-Cytotoxicity of C, DMC, BDMC in KB (3a), KBChR8-5 (3b), HeLa (3c) cells studied at various concentrations of curcuminoids were added and incubated for 24 hours in $37^{\circ} \mathrm{C}$. The experiments were conducted in triplicates and the values represent mean \pm S.D of three independent experiments. Curcumin $\downarrow$, DMC $\square, \mathrm{BDMC} \triangle$. The data of KB, KBChR8-5 and HeLa cells as mean \pm S.D $(n=3)$ shown in $3 a, 3 b, 3 c$ respectively.

\section{Discussion:-}

Cancer is a major worldwide public health problem. Treatment for cervical cancer using chemotherapeutic drugs can be possible in early cancer stages, but the major obstacle in treatment failure is due to development of drug resistance. The major impediment in cancer chemotherapy is multidrug resistance due to overexpression of $\mathrm{ABC}$ transporters. The overexpression of ABCB1 occurs in 40-50\% of cancer patients and is associated with poor clinical outcome (Jamroziak et al., 2004).

The mechanism of drug resistance is characterized by a decrease in drug accumulation resulting from overexpression of energy-dependent multidrug efflux pump known as multidrug transporter (ABC transporter). The major mechanism responsible to MDR in cancer cells is the overexpression of MDR-1 gene product resulting increased production of a 170,000 dalton p-glycoprotein in the plasma membrane associated with multiple drug resistance in drug resistance CHO cells (Ling and Thompson, 1974).

Overexpression of p-gp has been well established as the cause of the MDR phenotype in many in vitro selected drug resistant cell lines. KB cell lines have been used to catalog the changes in specific protein synthesis associated with the development of multidrug resistance results in reduced drug accumulation which might be caused by activating efflux or decreasing uptake of anticancer drugs. KB-V1 cells were selected by subjecting KB cells in a step-wise fashion to increasing concentration of vinblastine. KB-V1 cells have been shown to express only p-gp at a higher level on their plasma membrane. The level of p-gp in KB-V1 cell membrane is about $1 \%$ of total plasma membrane of drug resistant cell lines (Ambudkar et al., 1992).

Likewise colchicine resistance clone KBChR8-5 with multidrug resistance is derived from the KB cell line (Fojo et al., 1985). KBChR8-5 cells were selected by subjecting KB cell lines in a stepwise fashion to increase the concentration of colchicine (Akiyama et al., 1985). The amount of purified p-glycoprotein thus obtained accounted for approximately 3 to $4 \%$ of the total plasma membrane protein in colchicine-resistant mutant cell line (Riordan and Ling, 1979). As KB and its stepwise derivative KBChR8-5 cell lines have been characterized extensively with respect to the phenomenon of drug resistance proving overexpression of MDR1 gene, so we decided to use KB and 
KBChR8-5 cell lines to assess the effect of curcuminoids on the cytotoxic activity and expression of MDR 1 gene, to see whether introduction of curcuminoids reduced the drug resistance of the cells.

We analysed the presence of MDR1 gene in KB and KBChR8-5 cells by real time PCR. KBChR8-5 cells showed higher level of MDR1 gene expression at 7.1 fold increase in MDR1 when compared to KB cells, but KB cells showed very mild expression of MDR1 gene.

There are vast number of heterogenous class of molecules present in the diet they are generally called as phytochemicals includes vitamins like carotenoids and food polyphenols like, phytoalexins, phenolic acids indoles, flavonoids (Sporn and Suh, 2002). More than 10,000 phytochemicals have been described and among them flavanoids include about 6000 compounds (Hairborne, 1993). These phytochemicals play major role in chemotherapy for cancer patients. They are present in the herbal constituents fruits, berries and spices, In spices are mint, rosemary, garlic, piper nigrum, curcumin, ginseng, onion (Bansal et al., 2009). The traditional uses of turmeric or natural curcuminoids in folk medicine are multiple, including antioxidant, anti-cancer, anti-inflammatory, antifungal, anti-parasitic, anti-venom, anti-mutagenic activity in vitro, (Peret-Almeida, 2005).

Recently it was reported that the effect of curcuminoids was examined on the proliferation of MCF-7 human breast tumor cells that demethoxycurcumin was the best inhibition of MCF-7 cells followed by curcumin and bisdemethoxycurcumin (Simon, 1998). Bisdemethoxycurcumin (BDMC) is active for modulation of MDR-1 gene expression (Anuchapreeda, 2004).

Curcuminoids are curcumin and its derivaties varies in structure and pharmacological activity. Therefore it is important to obtain curcuminoid pigments in high purity for detailed study of their biological properties. Our present study demonstrates isolation and separation of curcuminoids in pure form, thin layer chromatography revealed that the $\mathrm{Rf}$ value of curcuminoids shown in TLC were $0.75,0.55$, and 0.27 , for C, DMC, BDMC respectively. Better resolution of Rf value showed that chloroform and methanol can be suitable solvent for the separation of compounds in column chromatography. Further purification results in curcumin as bright yellow needle shaped crystals, DMC as light yellow crystals, BDMC as reddish orange color crystals. The structure and purity of isolated curcuminoids were determined by GCMS, FTIR, and NMR. The purity of curcuminoids were analysed by HPLC from the percentage calculation using peak area and retention time, it was found to be $>95 \%$ purity for each compound.

The curcuminoids were found more toxic for cancer cells than normal cell line. In this regards, therapeutic index' is an important parameter to select samples for developing drugs. The result of our experiment revealed in MTT assay to determine the relative cytotoxicity of curcuminoids in KB and KBChR8-5 cell lines and HeLa cell lines. Each curcuminoids have different $\mathrm{IC}_{50}$ values in the range of $5-25 \mu \mathrm{M}$. There was a decrease in the viability of individual cell line with increasing concentration of curcuminoids treated. As HeLa cells are cancer cells that are used generally for cancer studies, the reaction with curcuminoids showed increased Cytotoxicity on curcumin treatment than DMC, BDMC in HeLa cells. The cytotoxic activity of curcumin may be due to inducing apoptosis by inhibiting proliferation of cancer cells by cell cycle arrest. Chearwae et al., studied cytotoxic activity of three curcuminoids on $\mathrm{KB}-\mathrm{V} 1$ and its parental cell lines results in $\mathrm{IC}_{50}$ range $25-90 \mu \mathrm{M}$ cytotoxicity of each compound on both cell lines are nearly equal. Curcumin showed greater cytotoxic effect (Chearwae et al., 2004).

KB and KBChR8-5 cell lines are derived from HeLa cell lines shows increased production of MDR-1 gene, BDMC act on MDR cell lines more effectively than other curcuminoids. The cytotoxicity of curcuminoids against drug resistant cell lines showed that higher cytotoxicity at BDMC treatment on KB and KBChR8-5. The $\mathrm{IC}_{50}$ value of drugs on MDR subline were nearly equivalent to that of parental cell line. Individual curcuminoids vary in chemical structure and the knowledge of structure-activity relationship in combination with conventional chemotherapy is useful for drug design. our result implies that BDMC act on MDR cell lines more effectively than other curcuminoids which revealed that it may have synergistic effect that target the site related to multidrug resistance and helps in accumulation of anticancer drugs by blocking the efflux pump to increase the cytotoxicity and induce apoptosis. BDMC can be used as effective chemosensitizer combination with conventional chemotherapy for circumventing MDR in cervical cancer. 


\section{Conclusion:-}

In summary, curcuminoids can inhibit tumor growth in drug resistant cell lines. BDMC in curcuminoids can synergistically induce the down regulation of MDR-1 gene and increase accumulation of anticancer drugs to produce typical apoptotic morphological changes. BDMC can be used as effective chemosensitizer combination with conventional chemotherapy for circumventing MDR in cervical cancer. Novelty in chemical structure further suggests its importance in future MDR tumor.

\section{Acknowledgement:-}

The authors are thankful to The Principal, The Head, Department of Plant Biology and Plant Biotechnology, Presidency College, Chennai - 600005 and Arjuna Natural Extracts, Alwaye, Kerala - 683 101, for providing laboratory facilities, and technical assistance.

\section{References:-}

1. Akiyama, S., Fojo, A., Hanover, JA., Pastan, I. and Gottesman, MM. (1985). Isolation and genetic characterization of human KB cell lines resistant to multiple drugs. Somat Cell Mol Genet. 11(2):117-126.

2. Ambudkar, SV., Cardarelli, CO., Pashinsky, I. and Stein, WD. (1997). Relation between the turnover number for vinblastine transport and for vinblastine-stimulated ATP hydrolysis by human P-glycoprotein. J Biol Chem. 272(34):21160-21166.

3. Anuchapreeda, S., Leechanachai, P., Smith, MM., Ambudkar, SV., and Limtrakul PN. (2002). Modulation of Pglycoprotein expression and function by curcumin in multidrug-resistant human KB cells. Biochem Pharmacol. 64(4):573-582.

4. Bansal, T., Jaggi, M., Khar, RK. and Talegaonkar, S. (2009). Emerging significance of flavonoids as Pglycoprotein inhibitors in cancer chemotherapy. J Pharm Pharm Sci. 12(1):46-78.

5. Biemann, K. (1962). "Mass Spectrometry - Organic Chemical applications" McGraw Hill Book Co. Inc., New York.

6. Borst, P., Evers, R., Kool, M. and Wijnholds, J. (2000). A family of drug transporters: the multidrug resistanceassociated proteins. J Natl Cancer Inst. 92(16):1295-1302.

7. Boshart, M., Gissmann, L., Ikenberg, H., Kleinheinz, A., Scheurlen, W. and Zur HH. (1984). A new type of papillomavirus DNA, its presence in genital cancer biopsies and in cell lines derived from cervical cancer. EMBO J. 3(5):1151-1157.

8. Chearwae, W., Anuchapreeda, S., Nandigam,a K., Ambudkar, S V., and Limtrakul, P. (2004). Biochemical mechanism of modulation of human P-glycoprotein (ABCB1) by curcumin I, II and III purified from turmeric powder. Biochemical pharmacology. 68:2043-2052.

9. Chomczynski P \& Sacchi N. Single-step method of RNA isolation by acid guanidinium thiocyanate-phenolchloroform extraction. Anal. Biochem. 162:156-9, 1987.

10. Colthup, NB., Daly, LH. and Wiberley, S E. (1990). Introduction to Infrared and Raman Spectroscopy. New York : academic.

11. Cooper, TH., Clark, G. and Guzinski, J. (1994). Food Phytochemicals II: Teas, Spices and Herbs (HOCT ed) American Society, Washington, DC. pg:231-236.

12. Fojo, A., Akiyama, S., Gottesman, MM. and Pastan, I. (1985). Reduced drug accumulation in multiply drugresistant human KB carcinoma cell lines. Cancer Res. 45(7):3002-3007.

13. Gottesman, MM. and Pastan, I. (1988). The multidrug transporter, a double-edged sword. J Biol Chem. 263(25):12163-12166.

14. Gottesman, MM. and Ling V. (2006). The molecular basis of multidrug resistance in cancer: the early years of P-glycoprotein research. FEBS Lett. 580(4):998-1009.

15. Govindarajan, VS. (1980). Turmeric - chemistry, Technology and Quality. CRC Critical Review in Food Science and Nutrition. 12(3), 199-301.

16. Gupta, AP., Gupta, MM. and Sushil kumar. (1999). Simultaneous determination of curcuminoids in curcuma samples using High Performance Thin Layer Chromatography. J.Liq.Chrom.\& Rel.Technol, 22(10):1561-1569.

17. Hairborne, JB. (1993). The flavanoids advances in research since 1986; Chapman \& Hall: London, UK. pg:1676.

18. James Carmichael, William, G., DeGraff Adi, F. and Gazdar. (1987) Evaluation of a Tetrazolium-based Semiautomated Colorimetric Assay: Assessment of Chemosensitivity Testing. Cancer Res. 47: 936-942.

19. Jamroziak, K. and Robak, T. (2004). Pharmacogenomics of MDR1/ABCB1 gene: the influence on risk and clinical outcome of haematological malignancies. Hematology. 9: 91-105. 
20. Kim, AN., Jeon, WK., Lee, JJ. and Kim, BC. (2010). Up-regulation of heme oxygenase-1 expression through CaMKII-ERK1/2-Nrf2 signaling mediates the anti-inflammatory effect of bisdemethoxycurcumin in LPSstimulated macrophages. Free Radic Biol Med. 49(3):323-331.

21. Leonard, GD., Polgar, O. and Bates, SE. (2002). ABC transporters and inhibitors: new targets, new agents. Curr Opin Investig Drugs. 3(11):1652-1659.

22. Ling, V. and Thompson, LH. (1974). Reduced permeability in CHO cells as a mechanism of resistance to colchicine. J Cell Physiol. 83(1):103-116.

23. Merina Benny Antony. (2003). Indigenous Medicinal Plants: their extracts and isolates as a value added export product. Journal Agro bios. 1: 39-41.

24. Mosmann, T.,. Rapid colorimetric assay for cellular growth and survival: application to proliferation and cytotoxicity tests. J. Immunol. Methods, 1983; 65, 55-63 Parkin DM(1), Bray

25. Nelson-Rees, WA. and Flandermeyer, RR. (1976). HeLa cultures defined. Science. 191(4222):96-98.

26. Peret-Almeida, L., Cherubino. and Alves, R.J. (2005). Separation and determination of the physico-chemical characteristics of curcumin, demethoxycurcumin, bisdemethoxycurcumin. Food Research International. 38:1039-1044.

27. Revathy, S., S. Elumalai, Merina Benny Antony and Benny Antony. 2011. Isolation, purification and Int.J.Curr.Microbiol.App.Sci (2013) 2(5): 28-39 identification of curcuminoids from turmeric (Curcuma longa L.) by column chromatography. J. Experi.Sci. 2(7): 21-25.

28. Sompol Paramapojn., and Wandee Gritsanapan. 2009. Free radical scavenging activity determination and quantitative analysis of curcuminoids in Curcuma zedoaria rhizome extracts by HPLC method. Curr.Sci. 97: 1069- 1073.

29. Slichter, CP. (1990). Principles of Nuclear Magnetic Resonance, $3^{\text {rd }}$ edn., Springer, New York.

30. Sporn, MB. and Suh, N. (2002). Chemoprevention: an essential approach to controlling cancer. Nat Rev Cancer. 2(7):537-543. 